\title{
KRAS and BRAF mutations are prognostic biomarkers in patients undergoing lung metastasectomy of colorectal cancer
}

\author{
S Renaud ${ }^{1,2}$, B Romain ${ }^{2,3}$, P-E Falcoz ${ }^{*}, 1$, A Olland ${ }^{1}$, N Santelmo ${ }^{1}$, C Brigand ${ }^{3}$, S Rohr ${ }^{3}$, D Guenot ${ }^{2}$ \\ and $G$ Massard ${ }^{1}$ \\ ${ }^{1}$ Department of Thoracic Surgery, Nouvel Hôpital Civil, Strasbourg University Hospital, Strasbourg 67000, France; ${ }^{2}$ EA 3430: \\ Tumoral progression and micro-environment, Translational and epidemiological approaches, Strasbourg University, Strasbourg \\ 67000, France and ${ }^{3}$ Department of General and Digestive Surgery, Hôpital de Hautepierre, Strasbourg University Hospital, \\ Strasbourg 67000, France
}

Background: We evaluated KRAS (mKRAS (mutant KRAS)) and BRAF (mBRAF (mutant BRAF)) mutations to determine their prognostic potential in assessing patients with colorectal cancer (CRC) for lung metastasectomy.

Methods: Data were reviewed from 180 patients with a diagnosis of CRC who underwent a lung metastasectomy between January 1998 and December 2011.

Results: Molecular analysis revealed mKRAS in 93 patients (51.7\%), mBRAF in 19 patients (10.6\%). In univariate analyses, overall survival (OS) was influenced by thoracic nodal status (median OS: 98 months for $\mathrm{pN}-, 27$ months for $\mathrm{pN}+, \mathrm{P}<0.0001$ ), multiple thoracic metastases (75 months vs 101 months, $P=0.008$ ) or a history of liver metastases ( 94 months vs 101 months, $P=0.04$ ). mBRAF had a significantly worse OS than mKRAS and wild type (WT) $(P<0.0001)$. The 5 -year OS was $0 \%$ for $m B R A F, 44 \%$ for mKRAS and $100 \%$ for WT, with corresponding median OS of 15,55 and 98 months, respectively $(P<0.0001)$. In multivariate analysis, WT BRAF (HR: 0.005 (95\% Cl: 0.001-0.02), P<0.0001) and WT KRAS (HR: 0.04 (95\% Cl: 0.02-0.1), P<0.0001) had a significant impact on OS.

Conclusions: mKRAS and mBRAF seem to be prognostic factors in patients with CRC who undergo lung metastasectomy. Further studies are necessary.

Colorectal cancer (CRC) is the third most frequently diagnosed cancer and the second most common cause of cancer-related deaths in the world (Weitz et al, 2005). In 2012, CRC was the second most diagnosed cancer in Europe with 450000 new cases and the second leading cause of death with 215000 cases (Ferlay et al, 2013). Up to nearly $50 \%$ of patients will experience metastases during their lives, mainly located in both the liver and the lung (August et al, 1984; McCormack et al, 1992). Thoracic metastasectomy of CRC remains controversial despite several published series that have reported a 5-year overall survival (OS) ranging from 20 to 60\% after surgery (Sauter et al, 1990; McAfee et al, 1992; Baron et al, 1996; Girard et al, 1996; Okumura et al, 1996; Zanella et al, 1997), compared with the 5-year OS of the conventional treatment with 5-fluorouracil (5-FU)-based chemotherapy that does not exceed 5\% (Poon et al, 1989). Because the resection of lung parenchyma can cause morbidity and always alters respiratory function, several risk factors for a poor outcome after thoracic surgery have been identified to help select appropriate candidates for surgery. These risk factors include a high preoperative level of carcinoembryonic antigen (CEA), a short disease-free survival (DFS), an association with hepatic metastases, the number of thoracic metastases, an incomplete resection or lymph node involvement (LNI; Adam et al, 2011; Zabaleta et al, 2011; Hamaji et al, 2012; Sclafani et al, 2013). However, the past few

*Correspondence: Professor P-E Falcoz; E-mail: pierre-emmanuel.falcoz@wanadoo.fr

Received 9 May 2014; revised 24 July 2014; accepted 19 August 2014

(c) 2015 Cancer Research UK. All rights reserved 0007-0920/15 
years have seen an increased understanding of the molecular alterations in tumours that has led to many changes in the management of patients. In particular, clinicians can offer a more accurate prognosis, predict tumour response to therapy and personalise treatment approaches more accurately (Karagkounis et al, 2013). Two of the proto-oncogenes present in CRC have been extensively studied: $V$-Ki-ras2 Kirsten rat sarcoma viral oncogene homolog (KRAS) and V-raf Murine sarcoma viral oncogene homolog $B 1(B R A F)$. The involvement of KRAS in the carcinogenesis of CRC, specifically its role in the development of adenocarcinoma of the large intestine, has been known for many years (Vogelstein et al, 1988; Karagkounis et al, 2013). Some studies have suggested that the KRAS mutation is an independent prognostic factor in paired primary and metastatic CRC (Conlin et al, 2005). Furthermore, it is well known that the presence of KRAS mutations is strongly associated with resistance to antiepidermal growth factor receptor (EGFR) therapies (Lievre et al, 2006; Karapetis et al, 2008; Diaz et al, 2012). In addition, the presence of the V600E mutation in the BRAF gene is associated with an increased risk of death in CRC patients (Samowitz et al, 2005; Richman et al, 2009; Roth et al, 2010; Price et al, 2011). Only one single study has previously evaluated the potential role of molecular markers (that is, EGFR KRAS and BRAF) as risk factors for early recurrence after lung metastasectomy of CRC (Schweiger et al, 2014). However, to the best of our knowledge, no studies have focused on the possibility of using both KRAS and BRAF as biomarkers in selecting appropriate candidates for thoracic metastasectomy of CRC. Thus, we evaluated whether patients with the mutant KRAS ( $m K R A S)$ and mutant BRAF (mBRAF) had worse OS after thoracic surgery than patients with wild-type (WT) $B R A F$ and KRAS.

\section{MATERIALS AND METHODS}

This study was approved by our Institutional Review Board. We retrospectively analysed the records of 265 consecutive patients with metastatic CRC who underwent a thoracic procedure in the Thoracic Surgery Department of Strasbourg University Hospital (France) from January 1998 to December 2011. Eighty-five patients for whom mutational status was unknown were excluded from the study. All of the patients were considered completely cured of their primary tumour at the time of thoracic metastasectomy, and all pulmonary metastases were metachronous. The decision to perform thoracic surgery was made by the multidisciplinary board in the presence of a certified thoracic surgeon. The only cases of extrathoracic metastases were in patients who had hepatic metastases.

Preoperative thoracic evaluation was performed by a chest computed tomography scan and, in more recent years, by an 18fluorodeoxyglucose positron emission tomography scan. Economical parenchymal resections, such as segmentectomy and wedge resections, were performed. In cases where multiple lesions were sited in the same lobe, a lobectomy was often chosen, whereas a pneumonectomy was carried out when various lobes presented multiple lesions that were not accessible to a less extensive resection or were centrally located. A sequential bilateral thoracotomy was preferred to a median sternotomy in the presence of bilateral metastases. A thoracotomy was preferentially offered because it allowed the surgeon to palpate the lung while assessing for metastases not revealed by the preoperative imaging. As routinely performed in our Department of Thoracic Surgery to obtain complete tumour resection, a radical mediastinal lymphadenectomy, consisting of the ablation of stations $4 \mathrm{R}, 7,8,9$ and 10 on the right side and stations $4 \mathrm{~L}, 5,6,7,8,9$ and 10 on the left side, was systematically performed regardless of the results of the preoperative imaging. The local resection was considered to be complete if both macroscopic palpable lesions and microscopic invasion were absent from the edges of the resection, as determined by a histopathologic examination.

All resected specimens were confirmed to be metastatic lesions of CRC by a senior pathologist. The mutation analyses of the KRAS and $B R A F$ genes were performed by extracting genomic DNA from formalin-fixed tissue slides or sections from the primary CRC tumour using the QIAamp DNA-formalin fixed tissue kit (Qiagen, Valencia, CA, USA). The amplification of regions of interest (that is, codon $12 / 13$ for KRAS mutations and V600E for BRAF mutations) was performed by PCR. Appropriate positive and negative controls were included. The PCR protocol was as follows: an initial denaturation at $95^{\circ} \mathrm{C}$ for $5 \mathrm{~min}$, followed by 40 cycles of amplification at $95^{\circ} \mathrm{C}$ for $40 \mathrm{~s}, 57^{\circ} \mathrm{C}$ for $40 \mathrm{~s}$ and $72{ }^{\circ} \mathrm{C}$ for $40 \mathrm{~s}$ and, finally, an elongation at $72^{\circ} \mathrm{C}$ for $10 \mathrm{~min}$. The oligonucleotide primers used for amplifying the KRAS codon $12 / 13$ were $5^{\prime}$-TGAT AGTGTATTAACCTTATGTG-3' (sense) and $5^{\prime}$-TTGTTGGATC ATATTCGTCC-3' (antisense); for BRAF, they were $5^{\prime}$-TCCTTTA CTTACTACACCTCAGATA- $3^{\prime}$ (sense) and $5^{\prime}$-GACCTTCAATG ACTTTCTAGTAAC-3' (antisense). The amplified products were then sequenced.

Patients were categorised according to age, performance status (according to World Health Organization (WHO) classification), gender, number of pulmonary metastases, unilateral or bilateral thoracic metastases, thoracic re-intervention, preoperative CEA, liver metastases, presence or absence of LNI, hiliar $v s$ mediastinal location of any LNI, DFS length and mutational status (that is, $K R A S, B R A F)$. WT patients were those possessing neither KRAS nor $B R A F$ mutations. DFS length was calculated from the surgery of the primary CRC to the first diagnosis of a thoracic or liver metastasis by imaging. OS was calculated from the first metastasectomy until death or the last follow-up. Locoregional recurrence-free survival (LRRFS) was defined as the time period between a thoracic metastasectomy and the first diagnosis of thoracic recurrence. Post-operative death was defined as inhospital death or that occurring within 30 days following surgery. The Charlson comorbidity index (CCI) was calculated for each patient. The CCI incorporates 19 chronic diseases weighted according to their association with mortality. We grouped patients according to their total score into the following established categories: 0 (no comorbidity); 1-2 (average); 3-4 (moderate); and $\geqslant 5$ (severe) (Charlson et al, 1987). Because patients were referred to our Department of Thoracic Surgery by multiple oncologists from different centres, we had no uniform protocols for neo-adjuvant and adjuvant chemotherapy. However, all of the chemotherapy regimens were based on 5-FU.

IBM SPSS (Armonk, NY, USA) v.20 was used for statistical analyses. Comparisons between groups were performed with $\chi^{2}$, Fisher or Student's $t$-tests when appropriate. Correlations between qualitative variables were assessed by calculating Cramer's $V$. The prognostic influence of variables on survival was assessed with a log-rank test and Cox proportional hazard models, whereas a binary stepwise logistic regression was performed to evaluate influence of variables on recurrence after thoracic surgery. A twoway ANOVA was conducted that examined interaction between discontinuous variables. All tests were two sided, and the variables were considered significant for $P$-values $<0.05$. All variables with $P$-values $<0.2$ were tested in multivariate analysis.

\section{RESULTS}

Clinical and molecular characteristics. The characteristics of the patients are listed in Table 1. Our population was mainly composed of males (62.2\%). Mean age of the patients at the time of their thoracic metastasectomy was 63.35 years old $( \pm 9.66)$, and the median follow-up time was 42 months (2-122). The primary 
Table 1. Comparison of primary demographic data and known prognostic factors of overall survival after thoracic metastasectomy between groups based on mutational status

\begin{tabular}{|c|c|c|c|c|}
\hline & Wild type & mKRAS & mBRAF & $P$-value \\
\hline$n$ & $68(37.8 \%)$ & $93(51.7 \%)$ & $19(10.6 \%)$ & - \\
\hline Age $>60$ years & $50(73.5 \%)$ & $62(66.7 \%)$ & $13(68.4 \%)$ & 0.64 \\
\hline WHO PS & - & - & - & 0.83 \\
\hline $\begin{array}{l}0(n=132) \\
1(n=48)\end{array}$ & $\begin{array}{l}49(72.1 \%) \\
19(29.9 \%)\end{array}$ & $\begin{array}{l}68(73.1 \%) \\
25(26.9 \%)\end{array}$ & $\begin{array}{r}15(78.9 \%) \\
4(11.1 \%)\end{array}$ & - \\
\hline $\mathrm{CCl}$ & - & - & - & $<0.0001$ \\
\hline $\begin{array}{l}0(n=19) \\
1(n=68) \\
2(n=46) \\
3(n=47)\end{array}$ & $\begin{array}{c}13(19.1 \%) \\
49(72.1 \%) \\
6(8.8 \%) \\
0\end{array}$ & $\begin{array}{c}6 \text { (6.5\%) } \\
16(17.2 \%) \\
37(39.8 \%) \\
34(36.6 \%)\end{array}$ & $\begin{array}{c}0 \\
3(15.8 \%) \\
3(15.8 \%) \\
13(68.4 \%)\end{array}$ & $\begin{array}{l}- \\
- \\
-\end{array}$ \\
\hline Gender & - & - & - & 0.34 \\
\hline $\begin{array}{l}\text { Male }(n=112) \\
\text { Female }(n=68)\end{array}$ & $\begin{array}{l}44(64.7 \%) \\
24(35.3 \%)\end{array}$ & $\begin{array}{l}56(60.2 \%) \\
43(39.8 \%)\end{array}$ & $\begin{array}{r}12(63.2 \%) \\
7(26.8 \%)\end{array}$ & - \\
\hline PT stage of the primary CRC & - & - & - & 0.001 \\
\hline $\begin{array}{l}\text { PT1 }(n=23) \\
\text { PT2 }(n=23) \\
\text { PT3 }(n=98) \\
\text { pT4 }(n=36)\end{array}$ & $\begin{array}{c}12(17.6 \%) \\
12(17.6 \%) \\
39(57.4 \%) \\
5(7.4 \%)\end{array}$ & $\begin{array}{l}11(11.8 \%) \\
10(10.8 \%) \\
51(54.8 \%) \\
21(22.6 \%)\end{array}$ & $\begin{array}{c}0(0 \%) \\
1(5.3 \%) \\
8(42.1 \%) \\
10(52.6 \%)\end{array}$ & $\begin{array}{l}- \\
- \\
-\end{array}$ \\
\hline $\mathrm{pN}$ stage of the primary CRC & - & - & - & 0.05 \\
\hline $\begin{array}{l}\text { pNO }(n=93) \\
p N+(n=87)\end{array}$ & $\begin{array}{l}32(47.1 \%) \\
36(52.9 \%)\end{array}$ & $\begin{array}{l}55(59.1 \%) \\
38(40.9 \%)\end{array}$ & $\begin{array}{r}6(31.6 \%) \\
13(68.4 \%)\end{array}$ & - \\
\hline Neo-adjuvant chemotherapy before CRC & - & - & - & 0.12 \\
\hline $\begin{array}{l}\text { Yes }(n=93) \\
\text { No }(n=87)\end{array}$ & $\begin{array}{l}38(55.9 \%) \\
30(44.1 \%)\end{array}$ & $\begin{array}{l}42(45.2 \%) \\
51(54.8 \%)\end{array}$ & $\begin{array}{r}13(68.4 \%) \\
6(31.6 \%)\end{array}$ & - \\
\hline Adjuvant chemotherapy after CRC & - & - & - & 0.02 \\
\hline $\begin{array}{l}\text { Yes }(n=106) \\
\text { No }(n=74)\end{array}$ & $\begin{array}{l}37(54.4 \%) \\
31(45.6 \%)\end{array}$ & $\begin{array}{r}52(55.9 \%) \\
41(44.1 \%)\end{array}$ & $\begin{array}{r}17(89.5 \%) \\
2(10.5 \%)\end{array}$ & - \\
\hline Age at time of metastasectomy & $62.29( \pm 9.82)$ & $64.74( \pm 8.59)$ & $64.42( \pm 10.2)$ & 0.24 \\
\hline Thoracic LNI & - & - & - & $<0.0001$ \\
\hline $\begin{array}{l}\text { Yes }(n=58) \\
\text { No }(n=122)\end{array}$ & $\begin{array}{c}0(0 \%) \\
68(100 \%)\end{array}$ & $\begin{array}{l}40(43 \%) \\
53(57 \%)\end{array}$ & $\begin{array}{c}18 \text { (94.7\%) } \\
1 \text { (5.3\%) }\end{array}$ & - \\
\hline$>1$ thoracic metastases $(n=88)$ & $20(29.4 \%)$ & $55(59.1 \%)$ & $13(68.4 \%)$ & $<0.0001$ \\
\hline Liver metastases $(n=27)$ & $6(8.8 \%)$ & $15(16.1 \%)$ & $6(31.6 \%)$ & 0.04 \\
\hline Pre-CEA $\geqslant 5(n=71)$ & $32(47.1 \%)$ & 31 (33.3\%) & $8(42.1 \%)$ & 0.21 \\
\hline DFS $<24$ months & $16(23.5 \%)$ & $33(35.5 \%)$ & 9 (47.4\%) & 0.09 \\
\hline
\end{tabular}

tumour was located in colon in half of the patients $(n=87)$. In total, 23 patients had stage pT1 and pT2 primary tumours (12.8\%), 98 patients had pT3 tumours (54.4\%) and 36 patients had pT4 tumours (20\%). Eighty-seven patients (48.3\%) exhibited peritoneal LNI at the time of CRC surgery. Otherwise, neo-adjuvant chemotherapy was administered in 93 cases before CRC surgery (51.7\%), whereas adjuvant chemotherapy following CRC surgery was administered in 106 patients $(58.9 \%)$. The mean DFS was 50.41 months $( \pm 47.58)$. Fifteen percent of the patients had developed at least one liver metastasis. The mean number of resected metastases was 2.37 $( \pm 1.54)$, and all patients exhibited complete local resection. A positive LNI was found in 58 patients (32.2\%), which was mediastinal in $36 \%$ of patients, although $49 \%$ developed multiple thoracic metastases. Bilateral metastases were found in $26 \%$ of the patients. In $49 \%$ of the patients, a neo-adjuvant treatment was initiated immediately before thoracic surgery, whereas $48 \%$ underwent an adjuvant treatment after thoracic metastasectomy. There were no in-hospital deaths; however, the post-operative mortality rate was $0.5 \%$. Six $(3.3 \%)$ patients were observed to experience leftsided laryngeal recurrent nerve palsies.
Molecular analysis revealed the mKRAS gene in 93 patients (51.7\%) and $m B R A F$ in 19 patients (10.6\%). The G12D mutation was found in 30 patients (32.3\%), G12V in 25 patients $(26.9 \%)$, G13D in 20 patients (21.5\%), G12C in 9 patients (9.7\%), G12S in 5 patients (5.4\%) and G12A in 4 patients (4.3\%). Patients with the mBRAF gene developed significantly more LNI than patients with WT or mKRAS in both thoracic ( 94.7 vs 0 or $43 \%$, respectively, $P<0.0001)$ and colorectal locations (68.4 vs 52.9 or $40.9 \%$, $P=0.05)$. Correlations between $m B R A F$ status and thoracic $\mathrm{pN}$ status (Cramer's $V=0.63, P<0.0001$ ) as well as colorectal $\mathrm{pN}$ status (Cramer's $V=0.14, P=0.06$ ) were noted. However, no correlations were observed between mKRAS status and either thoracic (Cramer's $V=0.006, P=0.94$ ) or colorectal $\mathrm{pN}$ status (Cramer's $V=0.009, P=0.36)$. $m B R A F$ patients were more likely than the other patients to develop more than one thoracic metastasis $(P<0.0001)$ and liver metastasis $(P=0.04)$. Otherwise, adjuvant chemotherapy after CRC surgery was significantly more frequent in $m B R A F$ patients $(P=0.02)$. Finally, the CCI score was significantly lower in WT patients than in both $m B R A F$ and $m K R A S$ patients $(P<0.0001)$. Data are shown in Table 1 . 
Overall survival. In univariate analyses, the thoracic nodal status significantly influenced the OS. Indeed, although the median OS was 98 months (95\% CI: 83.33-112.66) for $\mathrm{pN}$ - patients, it was four times less for $\mathrm{pN}+$ patients (27 months (95\% CI: 15.32 38.68), $P<0.0001)$. Having more than one thoracic metastasis $(75$ months $v s 101$ months, $P=0.008$ ) or a history of a liver metastasis (94 months vs 101 months, $P=0.04$ ) significantly worsened the OS. Moreover, $m B R A F$ patients had a significantly worse OS than $m K R A S$ and WT patients (Figure 1). Indeed, the 5-year OS was $0 \%$ for $m B R A F$ patients, $44 \%$ for $m K R A S$ patients and $100 \%$ for WT patients, with a corresponding median OS of 15, 55 and 98 months, respectively $(P<0.0001)$. The median $O S$ was significantly influenced by the type of KRAS mutation. Indeed, OS was 82 months (95\% CI: 34.19-128.81) for G13D patients, 60 months (31.74-88.25) for G12D patients, 48 months for G12V patients, 45 months (95\% CI: 28.34-61.66) for G12A patients, 37 months (95\% CI: 15.09-58.91) for G12C patients and not reached for G12S patients $(P=0.04)$. Because of the limited numbers of patients in these subpopulations of $m K R A S$, no further statistical analyses was performed. In addition, CCI significantly influenced median OS $(P<0.0001)$. Moreover, although the $\mathrm{pN}$ status of the CRC tumour did not significantly influence the OS $(P=0.24)$, the median OS was significantly influenced by the $\mathrm{pT}$ stage of the primary tumour $(P<0.0001)$. Patients who underwent neo-adjuvant chemotherapy before CRC surgery exhibited a worse OS $(P=0.07)$; however, this result was not significant, only approaching significance. However, patients who benefit from adjuvant chemotherapy exhibited a poorer OS $(P=0.007)$. Finally, neither gender, WHO performance status, DFS, neo-adjuvant and adjuvant treatments during the time period immediately before or after thoracic metastasectomy, preoperative CEA, the $\mathrm{pN}$ status of the primary CRC nor second pulmonary surgery for thoracic recurrence influenced the OS. Concerning thoracic recurrence, 93 (51.7\%) patients had experienced a thoracic recurrence. Among them, 30 were not deemed suitable for a second thoracic surgery because of a poor pulmonary testing forbidding surgery and/or the impossibility to achieve a complete resection because of too many pulmonary metastases. However, even nonsignificant, the median OS of patients who did not benefit from a second thoracic surgery was lower (65 months (95\% CI: 19.54-110.46) vs 98 months (95\% CI: 68.48-127.52),

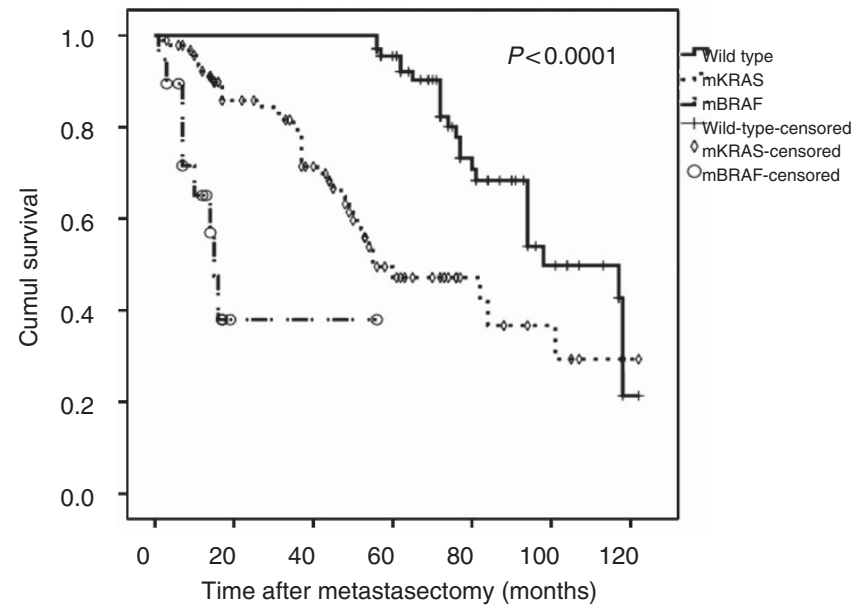

\begin{tabular}{|c|c|c|c|c|c|c|c|}
\hline $\begin{array}{c}\text { Patients } \\
\text { at risk } \\
\text { wild type }\end{array}$ & 68 & 68 & 68 & 58 & 29 & 12 & 1 \\
\hline $\begin{array}{c}\text { Patients } \\
\text { at risk } \\
m K R A S\end{array}$ & 93 & 63 & 46 & 20 & 9 & 5 & 1 \\
\hline $\begin{array}{c}\text { Patients } \\
\text { at risk } \\
m B R A F\end{array}$ & 19 & 1 & 1 & 0 & 0 & 0 & 0 \\
\hline
\end{tabular}

Figure 1. The Kaplan-Meier OS according to the mutational status (WT, mKRAS, mBRAF).
$P=0.54)$. Finally, there was significantly less $m B R A F$ patients who experienced a locoregional recurrence without surgery compared with mKRAS and WT patients (42.1 vs 72.1 and $77.4 \%$, respectively, $P=0.02$ ). Data are presented in Table 2 .

Because $m B R A F$ and $\mathrm{pN}$ status were correlated, a multivariate analysis model excluding $\mathrm{pN}$ status was employed (Table 3). CCI significantly influenced OS when patients with a CCI score of 0 were compared with patients with a CCI score of 1,2 and 3 $(P<0.0001)$. In addition, WT BRAF (HR: 0.005 (95\% CI: $0.001-0.02), P<0.0001)$ and WT KRAS (HR: 0.04 (95\% CI: $0.02-0.1), P<0.0001)$ had a significant impact on OS. Moreover, the absence of both liver metastasis and neo-adjuvant treatment before CRC surgery correlated with an upward trend in OS. Furthermore, adjuvant treatment following thoracic surgery, adjuvant treatment during the time period immediately before or after CRC surgery and the number of thoracic metastases did not achieve significance in the multivariate analysis. Finally, a two-way ANOVA was conducted that examined the effect of mutational status and LNI on OS. There was not a statistically significant interaction between the effects of mutational status and LNI on OS $(\mathrm{F}=2.033, P=0.134)$.

Because FOLFOX (folinic acid, 5-FU, oxaliplatin) chemotherapy regimen was approved by the Food and Drug Administration in 2004, OS was compared for patients who were treated before and after 2004. Median OS was not reached for patients who were treated after $2004(n=38)$ but was not significantly different from those treated before $2004(n=147$, median OS: 94 months, $95 \%$ CI: 6.94-80.39, $P=0.8)$.

Locoregional recurrence. At the end of the follow-up period, 93 $(51.7 \%)$ patients experienced a thoracic recurrence. Significantly more $m B R A F$ patients experienced a LRR compared with $m K R A S$ and WT patients $(100,46.2$ and $45.6 \%$, respectively, $P<0.0001$ ). Indeed, the risk of LRR was significantly increased in cases with $m B R A F$ status compared with both WT and mKRAS (odds ratio (OR): 19.87, $P<0.0001)$. No significant difference was noted concerning the risk of LRR and the type of KRAS mutation $(P=0.76)$. More patients with an elevated preoperative CEA experienced a LRR (60.6 vs 45.9\%, OR: 0.05, 95\% CI: $0.3-1.01$, $P=0.07$ ); however, this result was not significant, only approaching significance. Finally, no significant differences in the risk of LRR with respect to gender $(P=0.3)$, nodal status $(P=0.15)$, DFS $(P=0.15)$, the number of thoracic metastases $(P=0.77)$, history of liver metastases $(P=0.29)$ and neo-adjuvant $(P=0.23)$ and adjuvant treatments $(P=0.38)$ were noted.

Finally, based on multivariate analyses, an elevated preoperative CEA was the only prognostic factor of LRR (HR: 1.98 (95\% CI: 1.04-3.78), $P=0.04)$. Mutational status $(P=0.99)$, nodal status $(P=0.46)$ and DFS $(P=0.18)$ did not influence the LRR.

In univariate analyses, LRRFS was significantly influenced by the mutational status. Indeed, the median LRRFS of $m B R A F$ patients only reached 4 vs 31 months for mKRAS and 72 months for WT $(P<0.0001)$. The corresponding 5-year LRRFS were 0,18 and $69 \%$, respectively. Otherwise, the LRRFS was significantly lower in cases with a higher primary tumour pT stage $(P<0.0001)$, CRC and thoracic LNI ( $P=0.001$ and 0.04 , respectively), neoadjuvant and adjuvant chemotherapy around CRC surgery $(P=0.001$ and $<0.0001$, respectively), multiple thoracic metastases $(P=0.003)$, a history of liver metastases $(P=0.02)$ and adjuvant chemotherapy after thoracic surgery $(P=0.05)$. However, based on multivariate analyses, only the pT stage of the primary tumour $(P<0.0001)$ and mutational status remained independent prognostic factors. Indeed, both KRAS WT (HR: 0.16 (95\% CI: $0.07-0.33), P<0.0001$ ) and WT BRAF (HR: 0.04 (95\% CI: $0.02-$ $0.11), P<0.0001)$ were associated with better outcomes. Data are presented in Table 4. 
Table 2. Univariate analyses of overall survival (log-rank test)

\section{Variables} WHO PS

\begin{tabular}{r}
0 \\
1 \\
\hline $\mathrm{CC}$ \\
\hline 0 \\
\end{tabular}

Gender

Male

Female

Age

$\leqslant 60$ years old

$>60$ years old

PT stage of the primary tumour

PT1

pT2

PT3

PT4

$\mathrm{pN}$ stage of the primary tumour

$\mathrm{pNO}$

$\mathrm{pN}+$

Thoracic nodal status

pNO

$\mathrm{pN}+$

Neo-adjuvant chemotherapy before CRC

Yes

No

Adjuvant chemotherapy after CRC

Yes

No

Disease-free survival

$<24$ months

$\geqslant 24$ months

Number of thoracic metastases

1

$>1$

Liver metastases

Yes

No

Neo-adjuvant chemotherapy ${ }^{a}$

Yes

No

Adjuvant chemotherapy ${ }^{a}$

Yes

No

Preoperative CEA

$<5$

$\geqslant 5$

Re-surgery for thoracic recurrence

Yes

No

Mutational status

WT

MKRAS

MBRAF

Abbreviations: $C C$ =Charloon comorbidity index; $C R C=$ colorectal cancer; $m B R A F=m u$ tont BRAFi

WHO PS $=$ World Health Organization Performance Status. Bold values indicate significant $P$-values.

${ }^{a}$ Neo-adjuvant and adjuvant chemotherapy were administered before and after thoracic metastasectomy.
Median survival ( $95 \%$ confidence interval)

94 months (76.26-111.74)

82 months (46.06-117.94)

$-$

$118(116.53-119.46)$

$94(85.61-102.39)$

$55(52.30-57.71)$

$36(33.15-38.85)$

94 months $(80.7-107.3)$

80 months (69.42-90.58)

118 months (64.75-171.25)

82 months (70.91-93.09)

118 months

77 months (70.26-83.73)

94 months (82.22-105.78)

30 months (13.99-46)

98 months (53.57-142.43)

81 months (74.1-87.9)

98 months (83.33-112.66)

27 months (15.32-38.68)

81 months (75.25-86.75)

117 months (103.54-130.46)

80 months (72.69-87.3)

117 months (94.51-139.49)

84 months (70.63-97.36)

98 months (74.09-121.9)

-

101 months (72.33-129.66)

76 months (60-91.99)

94 months (82.18-105.82)

101 months

80 months (65.9-94.1)

94 months (75.66-112.33)

98 months (78.17-117.82)

77 months (58.42-95.58)

94 months (77.17-110.82)

84 months (64.61-103.39)

\begin{tabular}{c|c}
- & 0.84
\end{tabular}

84 months (73.68-94.32)

98 months (68.48-127.52)

98 months (74.21-121.78)

55 months (28.69-81.31)

15 months (12.17-17.83)
$P$-value

0.81

-

$<0.0001$

-

-

0.62

-

0.25

$-$

$-$

$<0.0001$

$-$

-

$-$

0.24

$-$

$-$

$<0.0001$

$-$

0.07

-

0.007

$-$

-

0.57

-

0.008

-

0.04

-

-

0.34

-

0.055

-

$-$

0.24

$-$

-

0.84

-

$<0.0001$

$-$

- 
Table 3. Multivariate analyses of overall survival (Cox proportional hazard model)

\begin{tabular}{|c|c|c|c|}
\hline Variables & HR & $95 \% \mathrm{Cl}$ & $P$-value \\
\hline pT of the primary tumour & - & - & 0.006 \\
\hline pT1 vs pT2 & 0.51 & $0.22-1.16$ & 0.11 \\
\hline pT1 vs pT3 & 0.51 & $0.16-1.62$ & 0.25 \\
\hline pT1 vs pT4 & 0.04 & $0.007-0.25$ & $<0.0001$ \\
\hline No neo-adjuvant chemotherapy before CRC surgery & 0.44 & $0.18-1.09$ & 0.07 \\
\hline Adjuvant chemotherapy following CRC surgery & 1.09 & $0.43-2.76$ & 0.85 \\
\hline Absence of liver metastases & 0.55 & $0.27-1.08$ & 0.08 \\
\hline Absence of $m K R A S$ & 0.04 & $0.02-0.1$ & $<0.0001$ \\
\hline Absence of $m B R A F$ & 0.005 & $0.001-0.02$ & $<0.0001$ \\
\hline Multiple thoracic metastases & 1.19 & $0.69-2.04$ & 0.52 \\
\hline No adjuvant chemotherapy after thoracic metastasectomy & 1.31 & $0.77-2.22$ & 0.31 \\
\hline $\mathrm{CCl}$ & - & - & $<0.0001$ \\
\hline 0 vs 1 & 0.01 & $0.003-0.04$ & $<0.0001$ \\
\hline 0 vs 2 & 0.08 & $0.03-0.02$ & $<0.0001$ \\
\hline 0 vs 3 & 0.43 & $0.21-0.87$ & 0.02 \\
\hline
\end{tabular}

\section{DISCUSSION}

Lung metastasectomy of CRC is steadily gaining acceptance in the field of thoracic surgery, although it remains a subject of debate because of the absence of recent comparisons between simple follow-up and surgery. However, published data support the idea that surgery, when technically feasible, remains the best approach for a subset of patients and leads to a 5-year OS ranging from 20 to 60\% (Sauter et al, 1990; McAfee et al, 1992; Baron et al, 1996; Girard et al, 1996; Okumura et al, 1996; Zanella et al, 1997). The historical treatment, which is based on 5-FU, leads to a 5-year OS of $5 \%$ (Poon et al, 1989). Because resection of the lung parenchyma can cause morbidity and always alters respiratory function, appropriate candidates for surgery must be clearly identified to avoid a surgery when the risks outweigh the benefits. To assist in evaluating patients for metastasectomy, several studies have tried to identify prognostic factors, namely, a high preoperative level of CEA, a short DFS, the presence of hepatic metastases, a number of thoracic metastases, an incomplete resection or LNI (Adam et al, 2011; Zabaleta et al, 2011; Hamaji et al, 2012; Sclafani et al, 2013). However, despite these clinical prognostic markers, some patients do not benefit from thoracic surgery, which leads to a search for other prognostic markers. During the past few years, the elucidation of molecular alterations in tumours has led to better management of patients by allowing the identification of subgroups of patients that harbour a different sensitivity to drugs or a different prognosis, such as an EGFR-activating mutation in non-small cell lung cancer (Kobayashi et al, 2005). In patients with CRC, two biomarkers have been the object of focus: the codon 12/ 13 mutation of KRAS and V600E of BRAF genes. However, to the best of our knowledge, our study is the first to focus on the role of these two biomarkers in selecting candidates suitable for surgery.

Most published series have reported an incidence of KRAS mutations in both localised and metastatic CRC ranging from 35 to 45\% (Andreyev et al, 1998, 2001; Lievre et al, 2006; Richman et al, 2009), whereas BRAF mutations are found in $8-10 \%$ of patients with metastatic CRC (Richman et al, 2009; Price et al, 2011). In our cohort, $52 \%$ of the patients carried the mKRAS gene, and $10 \%$ carried the $m B R A F$ gene. Our results are in line with two previous studies that reported a higher rate of $m K R A S$ in lung metastases than in liver metastases of patients with primary CRC. Indeed, Tie et al (2011) reported a rate of $62 \%$ of $m K R A S$ in lung metastases $v s$ $32.3 \%$ in liver metastases, and Cejas et al (2009) reported a rate of
$57 \%$ of mKRAS in case of lung metastases vs 35\% in liver metastases. Although our series reports a lower rate of KRAS mutations in patients with liver metastases compared with these two published series, $m K R A S$ was found in only $16 \%$ of patients with liver metastasis, and this supports the idea that there is a metastasis site-specific association of KRAS. However, given that incidence of these mutations were not known in patients in our cohort who did not meet the inclusion criteria, the interpretation of this association must be performed with caution. Schweiger et al (2014), in their work on molecular markers on 44 patients undergoing a pulmonary metastasectomy, did not observe $m B R A F$. However, the prevalence of $m B R A F$ of $10 \%$ might partially explain why in their relatively small population they did not observe this kind of mutation. Furthermore, the authors reported that $m K R A S$ was associated with multiple thoracic metastases. This is in accordance with our findings. Indeed, even if $m B R A F$ developed significantly more thoracic metastases than WT and $m K R A S$, the number of patients with multiple thoracic metastases was higher in the latter than in WT.

The published literature supports the idea that patients with metastatic CRC and KRAS mutations have the same prognosis as WT patients (Kastrinakis et al, 1995; Russo et al, 1998; Petrowsky et al, 2001; Hecht et al, 2009; Tol et al, 2010; Price et al, 2011). Nevertheless, no published study focused on OS in patients with lung metastases. We observed in paired univariate and multivariate analyses that $m K R A S$ negatively impacted OS after lung metastasectomy. However, even if the benefit of surgery for $m K R A S$ patients is not as high as for others, long-term survival can be achieved. Indeed, the 5 -year OS of $44 \%$ that is offered by surgery is superior to medical treatment. Furthermore, we observed that among those who carry a mutation in codon 12 , median OS was significantly better for those who carry the G12D mutation (60 months) and lower for those who carry the G12C mutation (37 months). Interestingly, our data are similar to those of Modest et $a l$, and two other papers that reported a poor prognosis in patients with the G12C mutation (Ihle et al, 2012; Fiala et al, 2013). In our cohort, however, we were unable to perform further statistical analyses to correlate this marker with clinical prognostic factors because the sub-population of patients with the KRAS mutation was small. However, the observations regarding $m K R A S$ mutations favour a correlation between different biological behaviours and the type of KRAS mutation. Further studies are necessary to understand the role of $m K R A S$ as a prognostic factor in lung metastases of CRC. 
Table 4. Univariate and multivariate analyses of LRRFS

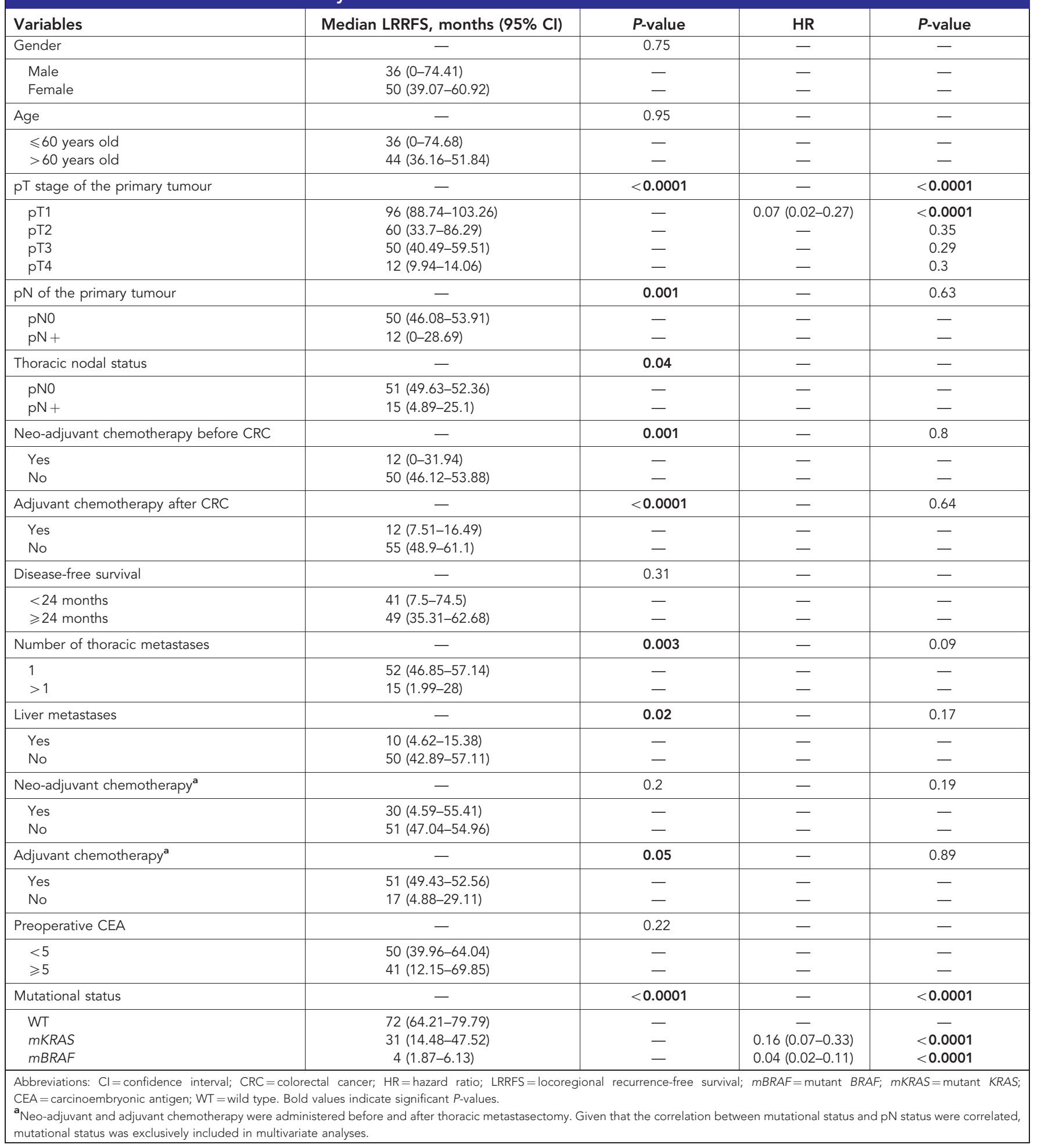

Patients with CRC who possess the mBRAF mutation have been shown to have a worse OS (Samowitz et al, 2005; Richman et al, 2009; Roth et al, 2010; Price et al, 2011). Our results confirm these data; patients with $m B R A F$ had an OS 3.5 times less than patients with $m K R A S$ and 6.5 times less than patients with the WT gene. This can be partially explained by the fact that those with $m B R A F$ developed significantly more thoracic and colorectal LNI and significantly more thoracic metastases, and were more likely to develop liver metastases, all of which are known to be negative prognostic factors. Tran et al (2011) also identified that $m B R A F$ patients were more likely to develop distant nodal metastases, as did Howell et al (2013), who observed a higher rate of nodal metastases of papillary thyroid cancer in these patients. Furthermore, we observed that $m B R A F$ patients were associated with increased $\mathrm{pT}$ stages of the primary CRC tumour, which negatively impacts the OS in our cohort. No previous studies have indicated that $m B R A F$ patients develop more liver metastases. It is possible that this significant result in our cohort might be related to the small number of patients rather than to a real association. However, to the best of our knowledge, our work is the first to 
report a link between $m B R A F$ and the number of thoracic metastases. These data, including a 5 -year OS of $0 \%$, support the idea that $m B R A F$ patients may not benefit from lung metastasectomy and should be excluded from thoracic surgery. However, due to the small number of patients in this group, no firm recommendation can be made.

Schweiger et al (2014) reported a significantly shorter time to pulmonary progression for $m K R A S$. We first observed that the risk of pulmonary recurrence was significantly higher for $m B R A F$, whereas the risk was not increased for mKRAS compared with WT patients. Nevertheless, we observed that recurrence did not negatively affect OS if an additional surgery was performed and a complete resection was achieved. On the other hand, based on both univariate and multivariate analyses, we observed that LRRFS was significantly influenced by mutational status. In particular, consistent with the previous publication of Schweiger et al, we observed that the LRRFS was significantly shorter for mKRAS patients (31 months). Moreover, we observed that LRRFS worsened for mBRAF patients, only reaching 4 months. This result appears to be another argument to contra-indicate surgery for $m B R A F$ patients.

We noticed that patients undergoing peri-operative treatments after CRC and thoracic surgery displayed reduced OS and LRRFS. However, peri-operative treatments were preferentially offered to patients with higher primary tumour $\mathrm{pT}$ stages, colorectal or thoracic LNI, and liver metastases and multiple thoracic metastases, all of which negatively impact OS and/or LRRFS. Furthermore, the different chemotherapy regimens are an important bias in the interpretation of this result. Consequently, no conclusions can be drawn from these results.

Our study has a few limitations that must be considered when analysing the results. First, it is a retrospective cohort study with a relatively small sample size. Moreover, the molecular data were obtained from the primary CRC and not from the metastatic tumours. Whether there is a concordance between the primary and the metastatic tumours remains a doubt, although Cejas et al (2009) reported a concordance of $94 \%$. In addition, some data that may partially impact the OS are lacking. We were not able to determine the interval that separated the liver or lung metastases from the CRC or the hepatic metastases. This may not be important because, according to Zabaleta et al (2011), the time between the hepatic resection and the lung metastasectomy does not affect survival. Nevertheless, patients with synchronous liver metastases and CRC have poorer survival. Our study also covers a 13 -year period, during which the management of patients could have changed, especially with the introduction of targeted therapies that might impact OS. Moreover, the different regimens of chemotherapy used could also have influenced the survival of studied patients. However, we particularly did not observe a significantly different OS after introduction of FOLFOX. Finally, even if the CCI score was significantly lower for WT patients, when analysed in multivariate analysis, the mutational status and the CCI were both independent prognostic factors.

In conclusion, our study is the largest to evaluate both $B R A F$ and KRAS mutations as biomarkers for selecting appropriate candidates with CRC for lung metastasectomy. These preliminary data suggest that the mutation status confers different clinical behaviours and show that these biomarkers may help to select candidates for lung metastasectomy. Thus, $m B R A F$ patients appear to be poor candidates, and the treatment regimen should be reviewed before thoracic surgery. Conversely, patients with the mKRAS mutation appear to benefit from lung surgery. Nevertheless, it appears that the different subtypes of $m K R A S$ confer different clinical implications, and because the prognostic and predictive values of the G12C mutations appear worse than those of other mutations, more studies are necessary. These results must be analysed with caution in light of the few limitations listed above; prospective trials of large cohorts are needed to confirm these preliminary results.

\section{ACKNOWLEDGEMENTS}

We thank Michèle Legrain, from the Molecular Biology Department of Strasbourg University Hospital, for her assistance in collecting data on molecular analysis.

\section{CONFLICT OF INTEREST}

The authors declare no conflict of interest.

\section{REFERENCES}

Adam R, de Haas RJ, Wicherts DA, Vibert E, Salloum C, Azoulay D, Castaing D (2011) Concomitant extrahepatic disease in patients with colorectal liver metastases: when is there a place for surgery? Ann Surg 253(2): 349-359.

Andreyev HJ, Norman AR, Cunningham D, Oates J, Dix BR, Iacopetta BJ, Young J, Walsh T, Ward R, Hawkins N, Beranek M, Jandik P, Benamouzig R, Jullian E, Laurent-Puig P, Olschwang S, Muller O, Hoffmann I, Rabes HM, Zietz C, Troungos C, Valavanis C, Yuen ST, Ho JW, Croke CT, O’Donoghue DP, Giaretti W, Rapallo A, Russo A, Bazan V, Tanaka M, Omura K, Azuma T, Ohkusa T, Fujimori T, Ono Y, Pauly M, Faber C, Glaesener R, de Goeij AF, Arends JW, Andersen SN, Lovig T, Breivik J, Gaudernack G, Clausen OP, De Angelis PD, Meling GI, Rognum TO, Smith R, Goh HS, Font A, Rosell R, Sun XF, Zhang H, Benhattar J, Losi L, Lee JQ, Wang ST, Clarke PA, Bell S, Quirke P, Bubb VJ, Piris J, Cruickshank NR, Morton D, Fox JC, Al-Mulla F, Lees N, Hall CN, Snary D, Wilkinson K, Dillon D, Costa J, Pricolo VE, Finkelstein SD, Thebo JS, Senagore AJ, Halter SA, Wadler S, Malik S, Krtolica K, Urosevic N (2001) Kirsten ras mutations in patients with colorectal cancer: the 'RASCAL II' study. Br J Cancer 85(5): 692-696.

Andreyev HJ, Norman AR, Cunningham D, Oates JR, Clarke PA (1998) Kirsten ras mutations in patients with colorectal cancer: the multicenter "RASCAL" study. J Natl Cancer Inst 90(9): 675-684.

August DA, Ottow RT, Sugarbaker PH (1984) Clinical perspective of human colorectal cancer metastasis. Cancer Metastasis Rev 3(4): 303-324.

Baron O, Amini M, Duveau D, Despins P, Sagan CA, Michaud JL (1996) Surgical resection of pulmonary metastases from colorectal carcinoma. Five-year survival and main prognostic factors. Eur J Cardiothorac Surg 10(5): 347-351.

Cejas P, Lopez-Gomez M, Aguayo C, Madero R, de Castro Carpeno J, Belda-Iniesta C, Barriuso J, Moreno Garcia V, Larrauri J, Lopez R, Casado E, Gonzalez-Baron M, Feliu J (2009) KRAS mutations in primary colorectal cancer tumors and related metastases: a potential role in prediction of lung metastasis. PLoS One 4(12): e8199.

Charlson ME, Pompei P, Ales KL, MacKenzie CR (1987) A new method of classifying prognostic comorbidity in longitudinal studies: development and validation. J Chronic Dis 40(5): 373-383.

Conlin A, Smith G, Carey FA, Wolf CR, Steele RJ (2005) The prognostic significance of K-ras, p53, and APC mutations in colorectal carcinoma. Gut 54(9): 1283-1286.

Diaz Jr LA, Williams RT, Wu J, Kinde I, Hecht JR, Berlin J, Allen B, Bozic I, Reiter JG, Nowak MA, Kinzler KW, Oliner KS, Vogelstein B (2012) The molecular evolution of acquired resistance to targeted EGFR blockade in colorectal cancers. Nature 486(7404): 537-540.

Ferlay J, Steliarova-Foucher E, Lortet-Tieulent J, Rosso S, Coebergh JW, Comber H, Forman D, Bray F (2013) Cancer incidence and mortality patterns in Europe: estimates for 40 countries in 2012. Eur J Cancer 49(6): 1374-1403.

Fiala O, Pesek M, Finek J, Benesova L, Belsanova B, Minarik M (2013) The dominant role of G12C over other KRAS mutation types in the negative prediction of efficacy of epidermal growth factor receptor tyrosine kinase inhibitors in non-small cell lung cancer. Cancer Genet 206(1-2): 26-31.

Girard P, Ducreux M, Baldeyrou P, Rougier P, Le Chevalier T, Bougaran J, Lasser P, Gayet B, Ruffie P, Grunenwald D (1996) Surgery for lung metastases from colorectal cancer: analysis of prognostic factors. J Clin Oncol 14(7): 2047-2053.

Hamaji M, Cassivi SD, Shen KR, Allen MS, Nichols FC, Deschamps C, Wigle DA (2012) Is lymph node dissection required in pulmonary metastasectomy for colorectal adenocarcinoma? Ann Thorac Surg 94(6): 1796-1800. 
Hecht JR, Mitchell E, Chidiac T, Scroggin C, Hagenstad C, Spigel D, Marshall J, Cohn A, McCollum D, Stella P, Deeter R, Shahin S, Amado RG (2009) A randomized phase IIIB trial of chemotherapy, bevacizumab, and panitumumab compared with chemotherapy and bevacizumab alone for metastatic colorectal cancer. J Clin Oncol 27(5): 672-680.

Howell GM, Nikiforova MN, Carty SE, Armstrong MJ, Hodak SP, Stang MT, McCoy KL, Nikiforov YE, Yip L (2013) BRAF V600E mutation independently predicts central compartment lymph node metastasis in patients with papillary thyroid cancer. Ann Surg Oncol 20(1): 47-52.

Ihle NT, Byers LA, Kim ES, Saintigny P, Lee JJ, Blumenschein GR, Tsao A, Liu S, Larsen JE, Wang J, Diao L, Coombes KR, Chen L, Zhang S, Abdelmelek MF, Tang X, Papadimitrakopoulou V, Minna JD, Lippman SM, Hong WK, Herbst RS, Wistuba II, Heymach JV, Powis G (2012) Effect of KRAS oncogene substitutions on protein behavior: implications for signaling and clinical outcome. J Natl Cancer Inst 104(3): 228-239.

Karagkounis G, Torbenson MS, Daniel HD, Azad NS, Diaz Jr. LA, Donehower RC, Hirose K, Ahuja N, Pawlik TM, Choti MA (2013) Incidence and prognostic impact of KRAS and BRAF mutation in patients undergoing liver surgery for colorectal metastases. Cancer 119(23): 4137-4144.

Karapetis CS, Khambata-Ford S, Jonker DJ, O'Callaghan CJ, Tu D, Tebbutt NC, Simes RJ, Chalchal H, Shapiro JD, Robitaille S, Price TJ, Shepherd L, Au HJ Langer C, Moore MJ, Zalcberg JR (2008) K-ras mutations and benefit from cetuximab in advanced colorectal cancer. N Engl J Med 359(17): 1757-1765.

Kastrinakis WV, Ramchurren N, Maggard M, Steele Jr G, Summerhayes IC (1995) K-ras status does not predict successful hepatic resection of colorectal cancer metastasis. Arch Surg 130(1): 9-14.

Kobayashi S, Boggon TJ, Dayaram T, Janne PA, Kocher O, Meyerson M, Johnson BE, Eck MJ, Tenen DG, Halmos B (2005) EGFR mutation and resistance of non-small-cell lung cancer to gefitinib. $N$ Engl J Med 352(8): 786-792.

Lievre A, Bachet JB, Le Corre D, Boige V, Landi B, Emile JF, Cote JF, Tomasic G, Penna C, Ducreux M, Rougier P, Penault-Llorca F, Laurent-Puig P (2006) KRAS mutation status is predictive of response to cetuximab therapy in colorectal cancer. Cancer Res 66(8): 3992-3995.

McAfee MK, Allen MS, Trastek VF, Ilstrup DM, Deschamps C, Pairolero PC (1992) Colorectal lung metastases: results of surgical excision. Ann Thorac Surg 53(5): 780-785.

McCormack PM, Burt ME, Bains MS, Martini N, Rusch VW, Ginsberg RJ (1992) Lung resection for colorectal metastases. 10-year results. Arch Surg 127(12): 1403-1406.

Okumura S, Kondo H, Tsuboi M, Nakayama H, Asamura H, Tsuchiya R, Naruke T (1996) Pulmonary resection for metastatic colorectal cancer: experiences with 159 patients. J Thorac Cardiovasc Surg 112(4): 867-874.

Petrowsky H, Sturm I, Graubitz O, Kooby DA, Staib-Sebler E, Gog C, Kohne CH, Hillebrand T, Daniel PT, Fong Y, Lorenz M (2001) Relevance of Ki-67 antigen expression and $\mathrm{K}$-ras mutation in colorectal liver metastases. Eur J Surg Oncol 27(1): 80-87.

Poon MA, O'Connell MJ, Moertel CG, Wieand HS, Cullinan SA, Everson LK, Krook JE, Mailliard JA, Laurie JA, Tschetter LK (1989) Biochemical modulation of fluorouracil: evidence of significant improvement of survival and quality of life in patients with advanced colorectal carcinoma. J Clin Oncol 7(10): 1407-1418.

Price TJ, Hardingham JE, Lee CK, Weickhardt A, Townsend AR, Wrin JW, Chua A, Shivasami A, Cummins MM, Murone C, Tebbutt NC (2011) Impact of KRAS and BRAF gene mutation status on outcomes from the Phase III AGITG MAX Trial of capecitabine alone or in combination with bevacizumab and mitomycin in advanced colorectal cancer. J Clin Oncol 29(19): 2675-2682.

Richman SD, Seymour MT, Chambers P, Elliott F, Daly CL, Meade AM, Taylor G, Barrett JH, Quirke P (2009) KRAS and BRAF mutations in advanced colorectal cancer are associated with poor prognosis but do not preclude benefit from oxaliplatin or irinotecan: results from the MRC FOCUS trial. J Clin Oncol 27(35): 5931-5937.
Roth AD, Tejpar S, Delorenzi M, Yan P, Fiocca R, Klingbiel D, Dietrich D, Biesmans B, Bodoky G, Barone C, Aranda E, Nordlinger B, Cisar L, Labianca R, Cunningham D, Van Cutsem E, Bosman F (2010) Prognostic role of KRAS and BRAF in stage II and III resected colon cancer: results of the translational study on the PETACC-3, EORTC 40993, SAKK 60-00 trial. J Clin Oncol 28(3): 466-474.

Russo A, Migliavacca M, Bazan V, Maturi N, Morello V, Dardanoni G, Modica G, Bazan P, Albanese I, La Farina M, Tomasino RM (1998) Prognostic significance of proliferative activity, DNA-ploidy, p53 and Ki-ras point mutations in colorectal liver metastases. Cell Prolif 31(3-4): 139-153.

Samowitz WS, Sweeney C, Herrick J, Albertsen H, Levin TR, Murtaugh MA, Wolff RK, Slattery ML (2005) Poor survival associated with the BRAF V600E mutation in microsatellite-stable colon cancers. Cancer Res 65(14): 6063-6069.

Sauter ER, Bolton JS, Willis GW, Farr GH, Sardi A (1990) Improved survival after pulmonary resection of metastatic colorectal carcinoma. J Surg Oncol 43(3): 135-138.

Schweiger T, Hegedus B, Nikolowsky C, Hegedus Z, Szirtes I, Mair R, Birner P, Dome B, Lang G, Klepetko W, Ankersmit HJ, Hoetzenecker K (2014) EGFR, BRAF and KRAS status in patients undergoing pulmonary metastasectomy from primary colorectal carcinoma: a prospective followup study. Ann Surg Oncol 21(3): 946-954.

Sclafani F, Incarbone M, Rimassa L, Personeni N, Giordano L, Alloisio M, Santoro A (2013) The role of hepatic metastases and pulmonary tumor burden in predicting survival after complete pulmonary resection for colorectal cancer. J Thorac Cardiovasc Surg 145(1): 97-103.

Tie J, Lipton L, Desai J, Gibbs P, Jorissen RN, Christie M, Drummond KJ, Thomson BN, Usatoff V, Evans PM, Pick AW, Knight S, Carne PW, Berry R, Polglase A, McMurrick P, Zhao Q, Busam D, Strausberg RL, Domingo E, Tomlinson IP, Midgley R, Kerr D, Sieber OM (2011) KRAS mutation is associated with lung metastasis in patients with curatively resected colorectal cancer. Clin Cancer Res 17(5): 1122-1130.

Tol J, Dijkstra JR, Klomp M, Teerenstra S, Dommerholt M, Vink-Borger ME, van Cleef PH, van Krieken JH, Punt CJ, Nagtegaal ID (2010) Markers for EGFR pathway activation as predictor of outcome in metastatic colorectal cancer patients treated with or without cetuximab. Eur J Cancer 46(11): 1997-2009.

Tran B, Kopetz S, Tie J, Gibbs P, Jiang ZQ, Lieu CH, Agarwal A, Maru DM, Sieber O, Desai J (2011) Impact of BRAF mutation and microsatellite instability on the pattern of metastatic spread and prognosis in metastatic colorectal cancer. Cancer 117(20): 4623-4632.

Vogelstein B, Fearon ER, Hamilton SR, Kern SE, Preisinger AC, Leppert M, Nakamura Y, White R, Smits AM, Bos JL (1988) Genetic alterations during colorectal-tumor development. N Engl J Med 319(9): $525-532$.

Weitz J, Koch M, Debus J, Hohler T, Galle PR, Buchler MW (2005) Colorectal cancer. Lancet 365(9454): 153-165.

Zabaleta J, Aguinagalde B, Fuentes MG, Bazterargui N, Izquierdo JM, Hernandez CJ, Enriquez-Navascues JM, Emparanza JI (2011) Survival after lung metastasectomy for colorectal cancer: importance of previous liver metastasis as a prognostic factor. Eur J Surg Oncol 37(9): 786-790.

Zanella A, Marchet A, Mainente P, Nitti D, Lise M (1997) Resection of pulmonary metastases from colorectal carcinoma. Eur J Surg Oncol 23(5): $424-427$.

This work is published under the standard license to publish agreement. After 12 months the work will become freely available and the license terms will switch to a Creative Commons AttributionNonCommercial-Share Alike 3.0 Unported License. 